\title{
Moderate maternal vitamin A deficiency affects perinatal organ growth and development in rats
}

\author{
Christos Antipatis*, George Grant and Cheryl J. Ashworth \\ The Rowett Research Institute, Bucksburn, Aberdeen AB21 9SB, Scotland, UK
}

(Received 14 April 1998 - Revised 21 October 1999 - Accepted 9 December 1999)

\begin{abstract}
Vitamin A deficiency during pregnancy is associated with detrimental effects in the offspring. We have developed a rat model to examine specific effects of maternal vitamin A status on perinatal growth and development. A total of 54 female rats were fed a vitamin A-free (VAF), -marginal (VAM) or -sufficient (VAS) diet from weaning until mating (at 7 weeks) and throughout pregnancy. Half of the rats in each group were injected with a single large dose of vitamin A on day 10 of pregnancy. Fetal and neonatal samples were taken on day 20 of pregnancy and the day of birth respectively. Maternal plasma retinol concentrations on day 20 and at birth were $50 \%$ and $30 \%$ lower in the VAF and VAM when compared to the VAS group. Fetal weight and survival did not differ between groups although placental : fetal ratio was higher in the VAF group than in the VAS group (0.195 (SE 0.005) v. 0.175 (SE 0.004), $P<0.05$ ). Rats fed the VAF diet gave birth at $23.5 \mathrm{~d}$, an average of $1 \mathrm{~d}$ later than the other groups, and had lower number of live neonates at birth. Fetal liver, heart and lung weights relative to total body weight were lower in the VAF group and had altered growth trajectories. In neonates, only the relative lung weight was reduced. In addition, an increased protein : DNA ratio indicated hypertrophy in fetal kidneys. Vitamin A injection had no additional effect on length of gestation and fetal or neonatal number. However, injection increased relative fetal organ weights in the VAF group but did not alter the effects of vitamin A deficiency in the neonate. These data suggest that chronic vitamin A deficiency during pregnancy compromises liver, heart and kidney and impairs lung growth and development during the last few days of gestation and reduces number of live neonates at birth.
\end{abstract}

Vitamin A: Fetus: Neonate: Pregnancy: Rats

Maternal vitamin A deficiency is recognised as a major public health problem in the developing world as it is associated with increased risk of fetal and infant mortality and morbidity (West, 1989; Katz et al. 1995). In many cases, clinical signs of vitamin A deficiency are not evident in the mother. However, problems arise because the rapidly developing fetus is vulnerable to a maternal deficiency without clinical symptoms (subclinical deficiency) (Underwood, 1994). Vitamin A exists in three oxidation forms as retinol, retinal and retinoic acid. Although the functions of vitamin A in prenatal development are still to be fully elucidated, it is known that vitamin $\mathrm{A}$ is an important factor in cell differentiation, maturation and morphogenesis of the embryo (DeLuca, 1991). There is limited evidence describing the effects of maternal vitamin A deficiency on human fetal development (Underwood, 1994). However, previous studies in the rat have demonstrated that maternal vitamin A deficiency can lead to infertility, high rates of spontaneous abortion, fetal malformation and late fetal death (Mason, 1935; Wilson et al. 1953; Thompson et al.
1964; Takahashi et al. 1975, 1977; Antipatis et al. 1996), but these have mainly been the result of severe vitamin A deficiency. Retinyl ester supplementation of vitamin Adeficient rat mothers during pregnancy has been reported to improve fetal growth (Takahashi et al. 1975). Furthermore, Wellik \& Deluca (1995) reported that supplementation of vitamin A-deficient rat dams with retinol on or before day 10 of pregnancy was associated with successful completion of gestation. The effects of maternal subclinical vitamin A deficiency during the later stages of pregnancy on fetal growth, organ development and number of live neonates at birth, or the level of supplementation required to overcome these effects, have not been examined in detail.

Vitamin A is transported from the liver to the target organs, including the fetus via the placenta. Homeostatic mechanisms regulate serum concentrations of vitamin A. Maternal serum vitamin A levels decline only when the liver is depleted in vitamin A (Wallingford \& Underwood, 1986). Fetal growth in the rat, as in most mammals, is very rapid during the last stage of pregnancy. Ismaldi \& Olson (1981), 
for example, observed a 30-fold increase in body weight between day 15 of pregnancy and the day of birth. During this period, transplacental transport of vitamin A to the fetus is extensive and highly regulated (Dann, 1932; Takahashi et al. 1977; Ismaldi \& Olson, 1981), resulting in a 60-fold increase in fetal whole-body vitamin A.

We have investigated the effects of a reduction of up to $50 \%$ (described as moderate deficiency by Lelievre-Pegorier et al. 1998) in maternal circulating vitamin A levels. The main objective was to determine the effects of this level of vitamin A deficiency on fetal and neonatal growth and development during the late stages of pregnancy and after birth in the rat which may help provide information of relevance to human subclinical deficiency. The effects of vitamin A (retinyl acetate) supplementation by injection at day 10 of pregnancy on fetal survival and number of live neonates at birth were also examined.

\section{Material and methods}

\section{Diets and experimental animals}

Corn oil was bought from Strachan and Sons (Aberdeen, Grampian, UK), while all other dietary ingredients were purchased from BDH Chemicals Co. or Sigma Chemicals Co. (both of Poole, Dorset, UK). At weaning (19d old), fifty-four female Rowett Hooded Lister rats were fed on three different diets (eighteen rats per diet). The first, a vitamin Afree (VAF) diet was formulated as in Table 1. The other two diets, vitamin A-marginal (VAM) and vitamin A-sufficient (VAS), were of the same composition but supplemented with 45 or 1200 retinol equivalents $/ \mathrm{kg}$ diet respectively. The diets were freely available throughout the experiment.

Table 1. Composition of the vitamin A-free diet $^{\star}$

\begin{tabular}{lc}
\hline Ingredient & $\mathrm{g} / \mathrm{kg}$ \\
\hline Lactalbumin & $162 \cdot 6$ \\
Corn starch & $362 \cdot 0$ \\
Potato starch & $100 \cdot 0$ \\
Glucose & $150 \cdot 0$ \\
Corn oil & $50 \cdot 0$ \\
Glycerol & $75 \cdot 0$ \\
Vitamin mixture† & $50 \cdot 0$ \\
Mineral mixtureł & $50 \cdot 0$ \\
Metasilicic acid & $0 \cdot 4$ \\
Total & $1000 \cdot 0$
\end{tabular}

* The diet contained approximately $18 \mathrm{MJ}$ metabolisable energy and approximately $15 \%$ crude protein per $\mathrm{kg}$ of diet. This is in accordance with the National Research Council (1995) recommendations for growth, maintenance and reproduction. Furthermore, $15 \%$ crude protein from a lactalbumin source covers all the requirements for essential amino acids.

† The vitamin mixture contained (per $\mathrm{kg}$ ): thiamine $200 \mathrm{mg}$, pyridoxine $200 \mathrm{mg}$ riboflavin $200 \mathrm{mg}$, $p$-aminobenzoic acid $200 \mathrm{mg}$, nicotinic acid $600 \mathrm{mg}$, calcium pantothenate $400 \mathrm{mg}$, folic acid $100 \mathrm{mg}$, biotin $100 \mathrm{mg}$, inositol $8000 \mathrm{mg}$ cholecalciferol $50 \mathrm{mg}$, all-rac- $\alpha$-tocopherol $1200 \mathrm{mg}$, menadione $2 \mathrm{mg}$, cyanocobalamin $5 \mathrm{mg}$, choline chloride $16 \mathrm{~g}$, made up to $1 \mathrm{~kg}$ with corn starch. In the vitamin A-marginal and vitamin A-sufficient diets, retinol (as retinyl acetate) (45 or 1200 retinol equivalents $/ \mathrm{kg}$ diet) was mixed with corn starch before adding to the diet. No vitamin A was added to the vitamin A-free diet.

¥ The mineral mixture contained (per kg): $\mathrm{CuSO}_{4} .7 \mathrm{H}_{2} \mathrm{O} 400 \mathrm{mg}, \mathrm{FeSO}_{4} .7 \mathrm{H}_{2} \mathrm{O}$ $5 \mathrm{~g}, \mathrm{MnSO}_{4} .4 \mathrm{H}_{2} \mathrm{O} 4 \mathrm{~g}, \mathrm{ZnSO}_{4} .7 \mathrm{H}_{2} \mathrm{O} 3.6 \mathrm{~g}, \mathrm{KI} 40 \mathrm{mg}, \mathrm{KIO}_{3} 40 \mathrm{mg}$, NaF $120 \mathrm{mg}, \mathrm{NH}_{4} \mathrm{VO}_{3} 10 \mathrm{mg}, \mathrm{NiCl}_{2} \cdot 6 \mathrm{H}_{2} \mathrm{O} 80 \mathrm{mg}, \mathrm{SnCl}_{4} \cdot 5 \mathrm{H}_{2} \mathrm{O} 120 \mathrm{mg}, \mathrm{NaSeO}_{3}$ $6 \mathrm{mg}, \mathrm{CrK}\left(\mathrm{SO}_{4}\right)_{2 .} 12 \mathrm{H}_{2} \mathrm{O}$ (chrome alum) $0.96 \mathrm{~g}, \mathrm{CaCO}_{3} 410 \mathrm{~g}, \mathrm{KH}_{2} \mathrm{PO}_{4}$ $314 \mathrm{~g}, \mathrm{KCl} 22 \mathrm{~g}, \mathrm{MgSO}_{4} .7 \mathrm{H}_{2} \mathrm{O} 102 \mathrm{~g}, \mathrm{Na}_{2} \mathrm{HPO}_{4} 142 \mathrm{~g}$, in about $1 \mathrm{~kg}$ (Grant et al. 1993).
Seven weeks post weaning, the female rats were mated with males of the same strain. Mating was confirmed by detection of a vaginal plug and day 0 was denoted. The female rats continued to be offered the VAF, VAM or VAS diets after mating.

On day 10 of pregnancy, nine rats from each dietary treatment received a $1 \mathrm{ml}$ subcutaneous injection containing $2.25 \times 10^{4}$ retinol equivalents per rat (retinyl acetate; Sigma Chemicals Co.) in $9 \mathrm{~g} \mathrm{NaCl} / \mathrm{l}$. This gave rise to a total of six groups of rats: VAF, VAF+ (vitamin A-free, injected), VAM, VAM+ (vitamin A-marginal, injected), VAS and VAS+ (vitamin A-sufficient, injected). Body weights were recorded three times per week before and after mating up to day 15 of pregnancy and then daily. Food intake was measured daily throughout the experiment. Four females from each group were killed on day 20 of pregnancy and the remaining five on the day of parturition. All mothers were killed by exsaguination under terminal anaesthesia induced by inhalation of halothane (Rhone Merieux Limited, Harlow, Essex, UK), while fetuses and neonates were killed by decapitation. The ovulation rate was determined by counting the number of corpora lutea in the maternal ovaries. The number of resorption sites observed in the uterus was recorded. All dead and live fetuses or neonates were counted and weighed. Maternal blood was collected from the carotid artery immediately after killing. The blood was centrifuged $\left(1000 \mathrm{~g}, 10 \mathrm{~min}, 4^{\circ} \mathrm{C}\right)$ and the plasma was stored at $-70^{\circ} \mathrm{C}$ for retinol analysis. All placentas and fetal liver, heart, kidneys, lungs and brain from up to eight live fetuses per litter were dissected, weighed and kept in liquid $\mathrm{N}_{2}$ for a maximum of $2 \mathrm{~h}$ and then stored at $-70^{\circ} \mathrm{C}$. Neonatal liver, heart, kidneys, lungs and brain from up to eight live neonates per litter were dissected, weighed and further stored at $-70^{\circ} \mathrm{C}$. Fetuses and neonates were visually assessed for normal gross morphology.

\section{Fetal and neonatal organ protein, DNA and RNA}

Fetal and neonatal liver, kidney and lung protein, DNA and RNA content were measured in VAF and VAS groups. Fetal or neonatal liver, lung or kidney tissue (200 mg per litter) were homogenised using a motor-driven Ultra-Turrax homogeniser with an $8 \mathrm{~mm}$ shaft (24000 r.p.m. for 10-20 s) (IKA Labortechnik, Staufen, Germany) in $4 \mathrm{ml}$ ice-cold perchloric acid (100 g/l) (BDH Chemicals Co.). The homogenate was left on ice to precipitate for $30 \mathrm{~min}$ and then centrifuged at $4000 \mathrm{~g}$ at $+4^{\circ} \mathrm{C}$ for $30 \mathrm{~min}$. The supernatant was removed. The residue was suspended in $5 \mathrm{ml} 0.3 \mathrm{M}-$ $\mathrm{NaOH}$ (Sigma Chemicals Co.) and incubated at $37^{\circ} \mathrm{C}$ for $1.5 \mathrm{~h}$. Of the solubilised residue solution, $1 \mathrm{ml}$ was kept for estimation of protein by a modified Lowry method (Schacterle \& Pollack, 1973). The remainder was mixed with an equal volume of perchloric acid (100 g/l) and kept at $+1{ }^{\circ} \mathrm{C}$ overnight. The precipitated protein and DNA were removed by centrifuging at $4000 \mathrm{~g},+4^{\circ} \mathrm{C}$ for $30 \mathrm{~min}$. The ribose content in the supernatant was determined by the orcinol reaction (Sneider, 1967). The DNA/protein precipitate was re-suspended in perchloric acid $(50 \mathrm{~g} / \mathrm{l})$, heated at $80^{\circ} \mathrm{C}$ for $60 \mathrm{~min}$, cooled on ice for $1 \mathrm{~h}$ and finally centrifuged at $1750 \mathrm{~g},+4^{\circ} \mathrm{C}$ for $10 \mathrm{~min}$. The deoxyribose content of the supernatant was measured with a diphenylamine reagent 
(Lovtrup \& Roos, 1961). Bovine serum albumin, calf liver RNA and calf thymus DNA (all from Sigma Chemicals Co.) were used as standards.

\section{Retinol analysis}

Maternal retinol plasma concentrations were determined by reverse phase HPLC as described by Hess et al. (1991) by using retinyl palmitate as an internal standard. All samples were analysed in duplicate. Intra- and inter-assay CV were $5.0 \%$ and $6.9 \%$ respectively.

\section{Statistical analysis}

Fetal survival and number of live neonates at birth were defined as the number of live fetuses or neonates expressed as a proportion of the total number of live, dead and resorbed fetuses or neonates. Data for maternal plasma retinol, maternal weight, duration of gestation, fetal survival and number of live neonates at birth were analysed by ANOVA in a 3 (diet) $\times 2$ (injection) experimental design using Genstat statistical package (Genstat 5, release 3.1, NAG Ltd, Oxford, UK). Mean values for fetal and neonatal body weights and placental: fetal ratios were calculated from all live fetuses or all live neonates respectively. In each group, fetal and neonatal relative organ weights were calculated from the fetuses or neonates dissected. These data were analysed by ANOVA in a 3 (diet) $\times 2$ (injection) experimental design using Genstat statistical package (NAG Ltd). Data for fetal and neonatal liver, kidney and lung protein, RNA, DNA content and protein : DNA ratio were analysed by ANOVA in a 2 (diet) $\times 2$ (fetus or neonate) experimental design using the Genstat statistical package (NAG Ltd). Differences were considered as significant at the $P<0.05$ level.

Linear regression was performed to examine the relationship between maternal plasma retinol concentration and number of live neonates at birth. A regression analysis was performed between the individual organ or placental weights and their corresponding fetal or neonatal body weights with the dietary treatment fitted to this analysis. The model used was as follows: organ weight $=$ intercept + body weight + diet + (body weight $\times$ diet $)$. Accumulated ANOVA for the data obtained from the regression analysis indicates the relationship between organ or placental weight and body weight and whether this relationship was affected by the diet fed to the pregnant rat. The interaction term indicates the homogeneity of the slope (i.e. it shows whether or not organ or placental weight was affected by body weight to the same extent across the different diets). Regression analysis was performed using the Genstat statistical package (NAG Ltd). Differences were considered as significant at the $P<0.05$ level.

\section{Results}

In each of the six groups there were three or four pregnant mothers on day 20 and four or five pregnant mothers at term. Data from non-pregnant rats were not included in the results. Fifteen of the seventeen rats given the VAM, VAM+, VAS or VAS+ diets gave birth on day 22, two gave birth $1 \mathrm{~d}$ later. Gestation length was significantly increased $(P<0 \cdot 001)$ in the VAF and VAF+ groups where only one rat delivered on day 22 and the remaining eight on day 23. No injection or interaction effects on the day of birth were observed.

Food intake and body weight did not differ significantly among any of the groups at any point during the pre-mating period (data not shown). Food intake did not differ amongst the different groups at any time point during pregnancy. Similarly, no differences were observed in daily weightgain between day 0 and day 19 of pregnancy. However, between day 20 and day 22, the weight of the females fed the VAF and VAF+ diets declined slightly. This was in contrast to the increases in weight observed in the females fed the remaining diets (Table 2). Administration of a high dose of vitamin A $10 \mathrm{~d}$ into pregnancy did not alter the

Table 2. Maternal weights, plasma retinol concentrations and reproductive outcome from pregnant rats fed vitamin A-free (VAF), vitamin Amarginal (VAM) and vitamin A-sufficient (VAS) diets without or with (+) vitamin A supplementation by injection on day 10 of pregnancy $\dagger$ (Mean values with standard errors for an initial subgroup of nine pregnant rats per diet)

\begin{tabular}{|c|c|c|c|c|c|c|c|c|c|c|c|c|c|c|c|c|c|c|c|c|c|}
\hline & \multicolumn{3}{|c|}{ VAF } & \multicolumn{3}{|c|}{ VAF+ } & \multicolumn{3}{|c|}{ VAM } & \multicolumn{3}{|c|}{ VAM+ } & \multicolumn{3}{|c|}{ VAS } & \multicolumn{3}{|c|}{ VAS+ } & \multicolumn{3}{|c|}{ ANOVA } \\
\hline & Mean & SE & $n$ & Mean & SE & $n$ & Mean & SE & $n$ & Mean & SE & $n$ & Mean & SE & $n$ & Mean & SE & $n$ & $\mathrm{D}$ & 1 & IN \\
\hline $\begin{array}{l}\text { Maternal weight at } \\
\text { mating }(\mathrm{g})\end{array}$ & $226 \cdot 6$ & $4 \cdot 30$ & 9 & $225 \cdot 3$ & 3.44 & 7 & $225 \cdot 3$ & $4 \cdot 37$ & 8 & 222.9 & $6 \cdot 39$ & 7 & $226 \cdot 5$ & 3.75 & 8 & $225 \cdot 6$ & 4.47 & 8 & - & - & - \\
\hline $\begin{array}{l}\text { Daily dietary intake } \\
\text { during pregnancy } \\
\text { (g/rat) }\end{array}$ & $19 \cdot 4$ & 0.4 & 9 & $19 \cdot 5$ & 0.3 & 7 & $19 \cdot 5$ & 0.3 & 8 & $19 \cdot 5$ & 0.3 & 7 & $19 \cdot 3$ & 0.3 & 8 & $19 \cdot 3$ & 0.3 & 8 & - & - & - \\
\hline $\begin{array}{l}\text { Maternal weight on day } \\
19 \text { of pregnancy }(\mathrm{g})\end{array}$ & 325.8 & $5 \cdot 48$ & 9 & $318 \cdot 6$ & $3 \cdot 67$ & 7 & $320 \cdot 1$ & $7 \cdot 84$ & 8 & $324 \cdot 6$ & $10 \cdot 49$ & 7 & 313.9 & $4 \cdot 12$ & 8 & $316 \cdot 2$ & $7 \cdot 50$ & 8 & - & - & - \\
\hline Plasma retinol $(\mu \mathrm{mol} / \mathrm{l})$ & 0.28 & 0.03 & 9 & 0.57 & 0.07 & 7 & 0.41 & 0.03 & 8 & 0.51 & 0.04 & 7 & 0.59 & 0.04 & 8 & 0.85 & 0.10 & 8 & $* * *$ & $* * *$ & - \\
\hline $\begin{array}{l}\text { Proportion of live } \\
\text { fetuses (d 20) }\end{array}$ & 0.95 & 0.03 & 4 & 1.00 & 0.01 & 3 & 0.97 & 0.02 & 4 & 0.96 & 0.04 & 3 & 0.96 & 0.04 & 4 & 1.00 & 0.01 & 3 & - & - & - \\
\hline $\begin{array}{l}\text { Weight gain between } \\
\text { day } 20 \text { and } 22(\mathrm{~g})\end{array}$ & -2.80 & 2.58 & 5 & -3.98 & $4 \cdot 13$ & 4 & $14 \cdot 17$ & 4.63 & 4 & 1.88 & 1.45 & 4 & 6.03 & 0.71 & 4 & $3 \cdot 33$ & 1.59 & 5 & * & - & - \\
\hline $\begin{array}{l}\text { Proportion of live } \\
\text { neonates (birth) }\end{array}$ & 0.49 & 0.08 & 5 & 0.30 & 0.16 & 4 & 0.84 & 0.09 & 4 & 0.54 & 0.16 & 4 & 0.84 & 0.09 & 4 & 0.89 & 0.08 & 5 & * & - & - \\
\hline
\end{tabular}

$D$, dietary vitamin $A ; I$, injection; IN, interactions.

${ }^{\star} P<0.05,{ }^{* \star \star} P<0.001$.

†For details of diets and procedures see Table 1 and p. 126 respectively. 
pattern of weight gain. Females fed the VAF and VAF+ diet continued to lose weight on day 23 (data not shown). Ovulation rate did not differ significantly among any of the groups as measured on day 20 or on the day of birth (data not shown).

Maternal plasma retinol concentrations did not differ between day 20 and day of birth within each group and the data from the two time points were pooled. Plasma retinol levels were reduced in the VAF and VAM groups when compared with the VAS group $(P<0 \cdot 001)$. Injection of vitamin A increased the plasma retinol levels in all injected groups when compared with the non-injected groups $(P<0.001)$. However, whilst the plasma retinol concentrations were increased by about $0.27-0.31 \mu \mathrm{mol} / 1$ in the VAF+ and VAS+ females, they were much less affected in VAM+ females (increased by approximately $0.11 \mu \mathrm{mol} / \mathrm{l}$ ) (Table 2). In the non-injected groups a positive correlation was observed between maternal plasma retinol concentrations and the number of live neonates at birth $(y=$ $3.92+10.20 x, P<0.05)$. However, this correlation was not apparent in the injected groups $(y=8 \cdot 60-2 \cdot 32 x, P>0 \cdot 05)$ (Fig. 1).

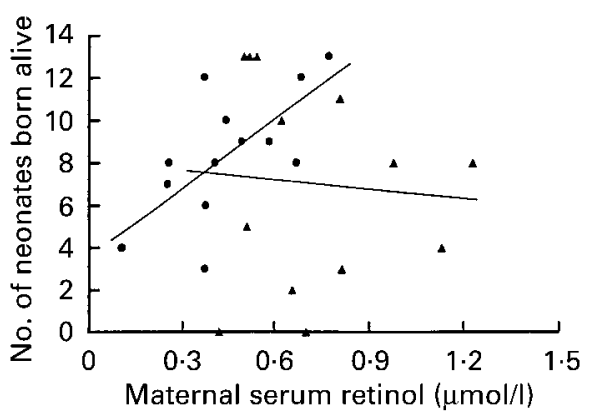

Fig. 1. Relationship between maternal plasma retinol concentration and number of live-born neonates in rats. Mothers were fed on a vitamin A-free, -marginal, or -sufficient diet (for details see Table 1) and received a vitamin $A$ supplement by injection $(\boldsymbol{\Lambda} ; y=8.6-2.32 x$, $P>0.05)$ of vitamin A on day 10 of pregnancy or not $(\mathbf{0} ; y=3.92+$ $10.20 x, P<0.05$ ) (for details of procedures see p. 126).
There were no significant effects of dietary vitamin A or injection on fetal survival or number of live fetuses on day 20 of pregnancy (Tables 2 and 3). There was, however, an effect of vitamin A deficiency on neonatal survival and the number of live neonates at birth which was reduced in the $\mathrm{VAF}$ and $\mathrm{VAF}+$ groups when compared with the VAM, $\mathrm{VAM}+$, VAS and VAS+ groups $(P<0 \cdot 05)$. Injection of vitamin A on day 10 of pregnancy did not alter neonatal survival or number of live neonates at birth (Tables 2 and 4).

There were significant differences in fetal weight due both to a dietary vitamin A deficiency and injection of vitamin A (both $P<0.05$ ) with both the VAF and VAF+ groups having lower fetal weights. There was also a significant $(P<0.05)$ interaction between dietary deficiency and injection. Vitamin A injection increased fetal weight when all the data were analysed by ANOVA. However, this increase due to injection was only evident in the VAS+ group which was $23 \%$ larger when compared with the VAS group (Table 3).

Placental weight was not affected by any of the treatments. However, due to the change in fetal weight, the placental : fetal weight ratio was significantly higher in both the VAF and VAF+ groups than the VAS and VAS+ groups $(P<0 \cdot 001)$. Injection of vitamin A reduced placental : fetal ratio $(P<0.05)$ particularly in the $\mathrm{VAM}+$ and $\mathrm{VAS}+$ groups (Table 3).

Relative lung weights were lower in fetuses from mothers fed VAF diet $(P<0.05)$ than fetuses from mothers fed VAS diet. This was the case whether the weights were expressed relative to body weight (Table 3 ), or in absolute terms, when lung weight was 81 (SE 2) and 82 (SE 3) mg in the VAF and $\mathrm{VAF}+$ groups respectively and 93 (SE 2) and 108 (SE 4) mg in VAS and VAS+ groups. Relative heart weights were lower in fetuses from mothers fed VAF diet $(P<0.05)$ than fetuses from mothers fed the remaining diets. Relative liver, brain and kidney weights were unaffected by dietary vitamin A deficiency. However, analysis by $t$ test revealed a significant $(P<0.05)$ decrease in the weight of the liver between groups VAF and VAS (Table 3). In absolute terms the liver weight was reduced from 216 (SE 4) mg in VAS to 171 (SE 6) $\mathrm{mg}$ in VAF. Injection of vitamin A did not affect

Table 3. Organ growth in day 20 fetuses collected from mothers receiving vitamin A-free (VAF), vitamin A-marginal (VAM) or vitamin A-sufficient (VAS) diets without or with (+) vitamin A supplementation by injection on day 10 of pregnancy $\dagger$

(Mean values with standard errors for pregnant rats or placental or fetal samples per group)

\begin{tabular}{|c|c|c|c|c|c|c|c|c|c|c|c|c|c|c|c|c|c|c|c|c|c|}
\hline & \multicolumn{3}{|c|}{ VAF } & \multicolumn{3}{|c|}{ VAF+ } & \multicolumn{3}{|c|}{ VAM } & \multicolumn{3}{|c|}{ VAM+ } & \multicolumn{3}{|c|}{ VAS } & \multicolumn{3}{|c|}{ VAS+ } & \multicolumn{3}{|c|}{ ANOVA } \\
\hline & Mean & SE & $n$ & Mean & SE & $n$ & Mean & SE & $n$ & Mean & SE & $n$ & Mean & SE & $n$ & Mean & SE & $n$ & $\mathrm{D}$ & I & IN \\
\hline No. of live fetuses/rat & $12 \cdot 00$ & 0.58 & & $12 \cdot 50$ & 0.50 & 3 & $12 \cdot 50$ & $1 \cdot 26$ & 4 & 12.50 & 1.50 & 3 & 10.50 & 2.02 & 4 & $9 \cdot 33$ & 3.67 & 3 & - & - & - \\
\hline Fetal weight (g) & $2 \cdot 78$ & 0.05 & 4 & 2.59 & 0.23 & 3 & 2.91 & 0.16 & 4 & $3 \cdot 11$ & 0.22 & 3 & 2.94 & 0.07 & 4 & $3 \cdot 61$ & 0.03 & 3 & * & * & * \\
\hline Placental weight (g) & 0.54 & 0.01 & 4 & 0.51 & 0.01 & 3 & 0.54 & 0.01 & 4 & 0.54 & $0 \cdot 01$ & 3 & 0.52 & 0.02 & 4 & 0.59 & 0.04 & 3 & - & - & - \\
\hline \multicolumn{22}{|c|}{ Fetal organ weights as a \% of total body weight } \\
\hline Lungs (\%) & 3.04 & 0.05 & 33 & 3.17 & 0.11 & 22 & 3.00 & 0.06 & 39 & 2.75 & 0.10 & 20 & 3.25 & 0.05 & 20 & 2.98 & 0.09 & 24 & * & - & * \\
\hline Heart (\%) & 0.40 & 0.02 & 28 & 0.56 & 0.03 & 22 & 0.54 & 0.03 & 33 & 0.52 & 0.40 & 18 & 0.58 & 0.03 & 28 & 0.47 & 0.02 & 18 & * & - & $* * *$ \\
\hline Liver (\%) & $6 \cdot 35$ & 0.17 & 33 & $6 \cdot 89$ & 0.26 & 22 & $6 \cdot 77$ & 0.16 & 39 & $6 \cdot 23$ & 0.22 & 20 & $7 \cdot 31$ & 0.14 & 35 & 6.07 & $0 \cdot 16$ & 24 & - & * & $* * *$ \\
\hline Brain (\%) & 4.01 & 0.13 & 28 & 4.56 & 0.15 & 16 & $4 \cdot 15$ & 0.11 & 33 & 4.63 & 0.08 & 18 & 4.15 & 0.19 & 28 & $4 \cdot 13$ & $0 \cdot 22$ & 18 & - & * & - \\
\hline Kidney (\%) & 0.80 & 0.04 & 28 & 0.89 & 0.05 & 16 & 0.86 & 0.03 & 33 & 0.81 & 0.04 & 18 & 0.79 & 0.04 & 28 & 0.87 & 0.06 & 18 & - & - & - \\
\hline $\begin{array}{l}\text { Placental : fetal weight } \\
\text { ratio }\end{array}$ & 0.20 & 0.01 & 48 & 0.20 & 0.00 & 36 & 0.19 & 0.01 & 50 & 0.17 & 0.01 & 37 & 0.18 & 0.01 & 37 & 0.16 & 0.00 & 28 & 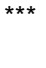 & * & - \\
\hline
\end{tabular}

$\mathrm{D}$, dietary vitamin $\mathrm{A} ; \mathrm{I}$, injection; IN, interactions.

${ }^{\star} P<0.05,{ }^{* \star *} P<0.001$.

†For details of diets and procedures see Table 1 and p. 126 respectively. 
Table 4. Organ growth in neonates collected from mothers receiving vitamin A-free (VAF), vitamin A-marginal (VAM) or vitamin A-sufficient (VAS) diets without or with (+) vitamin A supplementation by injection on day 10 of pregnancy $\dagger$

(Mean values with standard errors for pregnant rats or neonatal samples)

\begin{tabular}{|c|c|c|c|c|c|c|c|c|c|c|c|c|c|c|c|c|c|c|c|c|c|}
\hline & \multicolumn{3}{|c|}{ VAF } & \multicolumn{3}{|c|}{ VAF+ } & \multicolumn{3}{|c|}{ VAM } & \multicolumn{3}{|c|}{ VAM+ } & \multicolumn{3}{|c|}{ VAS } & \multicolumn{3}{|c|}{ VAS+ } & \multicolumn{3}{|c|}{ ANOVA } \\
\hline & Mean & SE & $n$ & Mean & SE & $n$ & Mean & SE & $n$ & Mean & SE & $n$ & Mean & SE & $n$ & Mean & SE & $n$ & $\mathrm{D}$ & I & IN \\
\hline No. of live neonates/rat & & 18 & 5 & & 1.0 & 4 & & 1.25 & 4 & 5 & 3.33 & 4 & 1 & 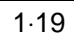 & 4 & 20 & 1.59 & 5 & . & - & $\overline{-}$ \\
\hline Neon & 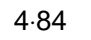 & 0.2 & 5 & & 0.2 & 4 & & 0.1 & 4 & 3 & 0.08 & 4 & & 0 . & 4 & & 0.43 & 5 & - & - & - \\
\hline L & 1.68 & 0.04 & 26 & 1.70 & 0.02 & 15 & 1.84 & 0.05 & 33 & 1.91 & 0.06 & 33 & 1.84 & 0.04 & 33 & 1.87 & 0.05 & 33 & * & - & - \\
\hline Heal & 0.67 & 0.03 & 26 & 0.64 & 0.06 & 15 & 0.60 & 0.02 & 30 & 0.61 & 0.02 & 30 & 0.61 & 0.02 & 30 & 0.62 & 0.02 & 30 & - & - & - \\
\hline Liver & $4 \cdot 20$ & 0.09 & 26 & 3.99 & $0 \cdot 11$ & 15 & 4.39 & $0 \cdot 10$ & 33 & 4.26 & 0.16 & 33 & 4.42 & 0.12 & 33 & 4.25 & $0 \cdot 10$ & 33 & - & - & - \\
\hline Brai & 4.43 & $0 \cdot 12$ & 26 & 4.64 & 0.41 & 15 & 4.23 & 0.18 & 30 & 4.40 & 0.08 & 30 & 4.36 & 0.11 & 30 & $4 \cdot 25$ & 0.13 & 30 & - & - & - \\
\hline Kidneys (g) & $1 \cdot 18$ & 0.03 & 26 & $1 \cdot 15$ & 0.07 & 15 & $1 \cdot 16$ & 0.03 & 30 & $1 \cdot 15$ & 0.03 & 30 & $1 \cdot 14$ & 0.03 & 30 & 1.08 & 0.04 & 30 & - & - & - \\
\hline
\end{tabular}

$\mathrm{D}$, dietary vitamin $\mathrm{A} ; \mathrm{I}$, injection; IN, interactions.

${ }^{*} P<0.05$.

†For details of diets and procedures see Table 1 and p. 126 respectively.

relative lung, heart and kidney weight but had significant effects on the liver and brain. Interaction of dietary deficiency and injection significantly affected relative lung $(P$ $<0.05)$, heart $(P<0.001)$ and liver $(P<0.001)$ weight; it increased relative lung, heart and liver weight in $\mathrm{VAF}+$ group when compared with VAF group but it reduced the relative weights of these organs in VAS+ group when compared with VAS group. Interaction of dietary deficiency and injection did not significantly affect relative brain and kidney weight (Table 3). There was no evidence of gross fetal or neonatal malformations.

Neonatal weight did not differ between the groups, despite the gestation period being an average of $1 \mathrm{~d}$ longer in the $\mathrm{VAF}$ and $\mathrm{VAF}+$ groups (Table 4). Relative neonatal lung weights were lower in both the VAF and $\mathrm{VAF}+$ groups than in the remaining groups $(P<0.05)$. In contrast, no differences were found in liver, heart, brain or kidney weights as a percentage of body weight between the neonatal groups due to dietary vitamin A deficiency. No effects from injection of vitamin A or interaction of dietary deficiency and injection were observed.

Protein content was reduced in kidneys on day of birth when compared with day 20 of pregnancy $(P<0.05)$. DNA content in kidneys was reduced in the VAF group when compared with the VAS group $(P<0 \cdot 05)$. In addition DNA content in liver was reduced on day of birth when compared with day 20 of pregnancy $(P<0 \cdot 05)$. Kidney protein : DNA ratio was higher in the VAF group when compared with the VAS group $(P<0.05)$. Kidney protein: DNA ratio was reduced on day of birth when compared with day 20 of pregnancy $(P<0 \cdot 05)$. Protein : DNA ratios in liver and kidneys showed significant dietary vitamin $\mathrm{A} \times$ day interactions (Table 5).

Regression analysis showed that organ weights $(P<$ $0.001)$ and placental weight $(P<0.05)$ were affected by the body weight of the fetus or the neonate. Liver, lung and

Table 5. Protein, RNA, DNA (mg/g) and protein: DNA ratio in liver, kidneys and lungs from live fetuses at day 20 of pregnancy and neonates at birth in vitamin A-free (VAF) and vitamin A-sufficient (VAS) diet groups $†$

(Mean values with standard errors for $n$ rat mothers per group)

\begin{tabular}{|c|c|c|c|c|c|c|c|c|c|c|c|}
\hline & \multicolumn{4}{|c|}{ Day 20} & \multicolumn{4}{|c|}{ Birth } & & & \\
\hline & \multicolumn{2}{|c|}{$\operatorname{VAF}(n 4)$} & \multicolumn{2}{|c|}{ VAS (n 4) } & \multicolumn{2}{|c|}{$\operatorname{VAF}(n 5)$} & \multicolumn{2}{|c|}{ VAS ( $n 4)$} & \multicolumn{3}{|c|}{ ANOVA } \\
\hline & Mean & SE & Mean & SE & Mean & SE & Mean & SE & $\mathrm{D}$ & $S$ & IN \\
\hline \multicolumn{12}{|l|}{ Liver } \\
\hline Protein & 194.3 & 27.9 & 209.9 & $17 \cdot 7$ & 226.9 & $22 \cdot 1$ & 152.9 & 3.7 & - & - & - \\
\hline RNA & 8.0 & 0.7 & 6.5 & 0.5 & $6 \cdot 7$ & 0.3 & $6 \cdot 2$ & 0.2 & - & - & - \\
\hline DNA & 3.1 & 0.3 & 2.6 & 0.1 & $2 \cdot 1$ & 0.1 & $2 \cdot 1$ & $0 . \overline{3}$ & - & * & _- \\
\hline Protein: DNA ratio & $64 \cdot 0$ & 13.5 & 82.2 & $6 \cdot 2$ & 107.5 & 8.5 & $86 \cdot 1$ & 8.4 & - & - & * \\
\hline \multicolumn{12}{|l|}{ Kidneys } \\
\hline Protein & 189.8 & $14 \cdot 4$ & 198.8 & 13.0 & $157 \cdot 9$ & 3.8 & 183.5 & 11.8 & - & * & - \\
\hline RNA & 5.3 & 0.2 & 5.8 & 0.5 & $5 \cdot 1$ & 0.5 & $5 \cdot 3$ & 0.3 & - & - & - \\
\hline DNA & 1.1 & 0.1 & $2 \cdot 3$ & 0.5 & 1.5 & 0.1 & $2 \cdot 3$ & 0.3 & * & - & - \\
\hline Protein : DNA ratio & 185.9 & 33.0 & 90.7 & 12.5 & $104 \cdot 7$ & 5.0 & $82 \cdot 0$ & 5.8 & * & * & * \\
\hline \multicolumn{12}{|l|}{ Lungs } \\
\hline Protein & $122 \cdot 4$ & $10 \cdot 0$ & $130 \cdot 2$ & $15 \cdot 9$ & $162 \cdot 3$ & 11.8 & 143.0 & $27 \cdot 7$ & - & - & - \\
\hline RNA & 5.9 & 1.3 & 4.0 & 0.3 & 4.4 & 0.8 & 2.6 & 0.2 & - & - & - \\
\hline DNA & 2.6 & 0.7 & 1.9 & 0.3 & $3 \cdot 2$ & 0.5 & $2 \cdot 4$ & 0.1 & - & - & - \\
\hline Protein: DNA ratio & 58.6 & $18 \cdot 7$ & $70 \cdot 9$ & $9 \cdot 4$ & $47 \cdot 3$ & 3.3 & $60 \cdot 4$ & 13.5 & - & - & - \\
\hline
\end{tabular}

$D$, dietary vitamin $A ; S$, stage of pregnancy; IN, interaction $(D \times S)$.

${ }^{*} P<0.05$.

†For details of diets and procedures see Table 1 and p. 126 respectively. 
Table 6. Intercepts and slopes of regression analyses and their accumulated analysis of variance between organ or placental weights and their total fetal or neonatal weights. The tissues were from fetuses (day 20) or neonates (day of birth) derived from pregnant rats fed on vitamin A-free (VAF), vitamin A-marginal (VAM) or vitamin A-sufficient (VAS) diets $†$

(Mean values with standard errors)

\begin{tabular}{|c|c|c|c|c|c|c|c|c|c|c|}
\hline & & \multicolumn{2}{|c|}{ VAF } & \multicolumn{2}{|c|}{ VAM } & \multicolumn{2}{|c|}{ VAS } & \multicolumn{3}{|c|}{ ANOVA } \\
\hline & & Mean & SE & Mean & SE & Mean & SE & $B$ & $\mathrm{D}$ & IN \\
\hline \multirow[t]{2}{*}{ Liver } & Intercept & 0.105 & 0.013 & 0.145 & 0.013 & 0.201 & 0.015 & & & \\
\hline & Slope & 0.022 & 0.003 & 0.017 & 0.003 & 0.003 & 0.003 & $* * *$ & $* * *$ & $* * *$ \\
\hline \multirow[t]{2}{*}{ Lungs } & Intercept & 0.067 & 0.006 & 0.071 & 0.006 & 0.091 & 0.007 & & & \\
\hline & Slope & 0.004 & 0.002 & 0.005 & 0.002 & 0.000 & 0.001 & $* * *$ & * & - \\
\hline \multirow[t]{2}{*}{ Heart } & Intercept & -0.013 & 0.002 & -0.001 & 0.002 & -0.001 & 0.003 & & & \\
\hline & Slope & 0.009 & 0.001 & 0.006 & 0.001 & 0.006 & 0.001 & $\star * *$ & - & $* * *$ \\
\hline \multirow[t]{2}{*}{ Kidneys } & Intercept & -0.018 & 0.004 & -0.012 & 0.003 & -0.024 & 0.004 & & & \\
\hline & Slope & 0.015 & 0.001 & 0.013 & 0.001 & 0.016 & 0.001 & $\star \star * *$ & - & * \\
\hline \multirow[t]{2}{*}{ Brain } & Intercept & -0.006 & 0.012 & 0.017 & 0.012 & 0.002 & 0.013 & & & \\
\hline & Slope & 0.044 & 0.003 & 0.035 & 0.003 & 0.042 & 0.003 & $* * *$ & - & - \\
\hline \multirow[t]{2}{*}{ Placenta } & Intercept & 0.209 & 0.086 & 0.410 & 0.072 & 0.469 & 0.131 & & & \\
\hline & Slope & 0.119 & 0.031 & 0.040 & 0.025 & 0.013 & 0.045 & * & * & - \\
\hline
\end{tabular}

$\mathrm{B}$, body weight; $\mathrm{D}$, dietary vitamin $\mathrm{A}$; IN, interaction (body weight $\times$ dietary vitamin $\mathrm{A}$ ).

${ }^{\star} P<0.05,{ }^{\star * \star} P<0.001$.

†For details of diets and procedures see Table 1 and p. 126 respectively.

placental weights were affected by the different diets. The intercept was lower in VAF and VAM groups than VAS group in both liver $(P<0.001)$ and lungs $(P<0.05)$. In placenta the intercept was lower in VAF group than VAM and VAS groups $(P<0 \cdot 05)$; the same pattern was observed for the heart, however differences did not reach significance. Liver, heart and kidney were affected by the weight $\times$ dietary vitamin A interactions. This was reflected in the differences seen in the slope which was higher in the VAF and VAM groups than the VAS group in liver $(P<0 \cdot 001)$. In the heart, the slope was higher in the VAF than the VAM and VAS groups $(P<0 \cdot 001)$. In the kidneys the slope was higher in the VAM than the VAF and VAS groups $(P<$ 0.05) (Table 6).

\section{Discussion}

A rat model of maternal vitamin A deficiency during pregnancy has been developed to assess the effects of deficiency on fetal survival, number of live neonates at birth, growth and development. It was also used to examine the effectiveness of supplementing pregnant females by injection with vitamin A during mid-pregnancy in counteracting problems associated with vitamin A deficiency.

\section{Vitamin A status and reproductive outcome}

In the current experiment plasma retinol concentrations were reduced by over $50 \%$ following 10 weeks of vitamin A deficiency. This is similar to the data reported by Wallingford \& Underwood (1987). A $50 \%$ reduction in rat plasma retinol concentrations indicates that the main reserve of vitamin $\mathrm{A}$ in the liver is depleted (Wallingford \& Underwood, 1987; Gardner \& Ross, 1993). Maternal plasma and maternal diet thus became the main sources of available vitamin $\mathrm{A}$ at this time, but both of these sources were limited in VAF and indeed VAM animals. This would have coincided with the 60 -fold increase in fetal vitamin A requirement during the third trimester of pregnancy when it is vital for growth and development (Takahashi et al. 1977; Ismaldi \& Olson, 1981). As fetal liver cannot store vitamin A in large quantities (Ismaldi \& Olson, 1981), an adequate and continuous maternal supply of vitamin A is essential.

Reducing the vitamin A content of the diet did not significantly affect the ovulation rate, occurrence of fetal resorption or fetal deaths, or the number of live fetuses on day 20 of pregnancy. This is in contrast to the effects of more severe vitamin A deficiency reported previously (Takahashi et al. 1975; Antipatis et al. 1996) and suggests that our model of vitamin A deficiency had no effects on fertilisation, implantation or early fetal growth, possibly because there were still sufficient maternal vitamin A stores in the liver to meet requirements in early pregnancy.

Low maternal vitamin A levels in the VAF group during the later stages of pregnancy delayed the time of parturition and significantly reduced the number of live neonates at birth. This suggests that maternal vitamin A deficiency may affect the mechanisms by which parturition is initiated. Our data are in agreement with those of Takahashi et al. (1975) who observed a reduced number of live neonates of similar mean weight to controls when maternal serum retinol concentrations dropped to approximately $50 \%$ of those in control rats.

A single high-dose injection of vitamin A approximately half-way through pregnancy increased maternal plasma retinol concentrations in all groups during the late stages of pregnancy, although the increase in the VAM group was less profound than in the other two groups. However, it did not change the reproductive outcome or number of live neonates at birth in any treatment group. This differs from the observations of Wellik \& DeLuca (1995) who found that the fetal resorption seen in vitamin A deficient rats could be prevented by administration of retinol on day 10 of pregnancy. We did not observe a significant number of resorption sites in any of the groups. This difference probably relates to the severity of the vitamin A deficiency. It appears that a large injection of vitamin A on day 10 of pregnancy in mothers consuming diets devoid of vitamin A may not 
correct the detrimental effects of low vitamin A status later in gestation on outcome of pregnancy.

High intakes of vitamin A in pregnancy have previously been associated with teratogenic effects in rats and humans (Collins et al. 1994). In the present study, vitamin A supplementation did not apparently cause fetal and/or neonatal malformation or additional neonatal death. This is in accordance with results of Biesalski et al. (1996) who also observed high maternal plasma vitamin A concentrations without fetal malformation in rat dams fed diets high in vitamin A $\left(5.25 \times 10^{4}\right.$ retinol equivalents $/ \mathrm{kg}$ diet $)$ throughout pregnancy. These authors suggested that the form of vitamin A administered is important for the teratogenic effect of vitamin A. Possible explanations include the inability of retinyl esters to cross the placental barrier or, alternatively, the low transformation of retinyl esters to retinoic acid and its derivatives. However, Biesalski et al. (1996) administered a high dose of vitamin A by diet rather than by injection, so this could result in differences of vitamin A availability to the organism due to different routes of administration.

\section{Placental development}

The effects of maternal vitamin A deficiency on fetal growth and development are thought to be mediated through the placenta (Takahashi et al. 1975, 1976). In the present study fetal weights were only slightly affected by any of the dietary treatments but placental : fetal ratio was increased in dams fed diets deficient in vitamin A. This is consistent with findings from studies in rats, sheep and humans into the effects of specific forms of maternal undernutrition during pregnancy. In the present study, the greater slope obtained by regression analysis from the vitamin A-deficient group confirms that dietary vitamin A deficiency can affect the balance between placenta and fetus.

In our rat model, although placental:fetal ratio was increased and placental growth trajectory was affected in the VAF group, before the final stages of pregnancy, fertility, implantation and fetal weights were only slightly affected. This suggests that rats were well nourished around conception and the effects of maternal vitamin A deficiency seen occurred only in the later stages of pregnancy, making our model useful for the study of specific effects of maternal vitamin A deficiency at this time. Overall, increased fetal weight due to injection of vitamin A resulted in a reduced placental: fetal ratio suggesting that, in contrast to fetal growth, placental growth is not affected by vitamin A injection.

\section{Fetal and neonatal organ development}

Fetal organ development was impaired by vitamin A deficiency. This is believed to be the first experimental animal model where maternal vitamin A deficiency has been shown to affect fetal development in the absence of other general malnutrition problems. Reduction in relative fetal lung weight persisted at birth indicating growth retardation of this organ. Relative liver, heart and lung weights were only reduced in the fetus and this may be explained by the increased duration of pregnancy in the VAF group or by compensatory growth. In contrast to our findings, Takahashi et al. (1975) observed that neonates from rats fed a diet restricted in vitamin $\mathrm{A}$, which resulted in a $50 \%$ reduction of serum vitamin $\mathrm{A}$, had smaller livers and kidneys than controls. The changes in organ weights can be attributed to retinoic acid which is crucial for structural as well as developmental changes during development of these organs (Fraslon \& Bourbon, 1994; Smith et al. 1997). This role of retinoic acid could also explain the increased relative organ weight in fetuses from mothers fed a vitamin A-deficient diet but injected with the vitamin.

Expressing fetal and neonatal organ weight as a percentage of whole-body weight is useful for determining the relative growth of the organ at one time point. However, it reveals little about the preceding developmental process. The effects seen in the lungs indicate that lung growth was impaired due to vitamin A deficiency. The regression analysis takes account of changes in relative organ weight with time and demonstrates that by delaying growth, vitamin A deficiency affects the growth trajectory of the developing liver and heart. Furthermore, the increased protein:DNA ratio, particularly in fetal kidneys from the VAF group, suggests that although relative fetal or neonatal kidney weight does not appear to be affected, kidney development may exhibit compensatory changes to effects induced by vitamin A deficiency before day 20. In contrast, the VAM diet which affected the kidney growth trajectory may act at a later stage of kidney development. Indeed, Lelievre-Pegorier et al. (1998) suggested that mild vitamin A deficiency reduces the number of nephrons in day 21 fetal kidneys.

The lungs were the only organ which was lighter in both fetuses and neonates from vitamin A-deficient mothers. This observation is of particular significance for humans because premature babies are often born deficient in vitamin $\mathrm{A}$ and are at high risk of developing lung diseases such as bronchopulmonary dysplasia (Chytil, 1992). Retinol and/or retinoic acid are important factors involved in differentiation and integrity of many epithelial cell types including those in the lungs and the trachea (Boren et al. 1974; Chytil, 1992). Major structural and functional changes occur in these tissues during the last few days of pregnancy to ensure that the fetus is viable at birth. It is perhaps not surprising therefore that maternal vitamin A deficiency at this stage appears to cause 'compensatory growth' of the liver, heart, kidneys and impaired growth of the lungs.

\section{Conclusions}

The rat model presented in this present paper clearly demonstrates that maternal vitamin A deficiency during pregnancy has deleterious effects on fetal development and viability. Increased severity of vitamin A deficiency is likely to further exacerbate the problem. A single high dose of vitamin A on day 10 failed to improve the outcome of pregnancy even though it increased relative fetal organ weight. The model presented in this paper provides the means to study the extent and nature of developmental and structural changes in fetal organs arising from moderate maternal vitamin A deficiency during pregnancy. It also allows the testing of therapeutic strategies to counteract the deleterious effects of vitamin A deficiency. 


\section{Acknowledgements}

This work was supported and funded by SOAEFD as part of the core funding to the Rowett Research Institute. Christos Antipatis was a recipient of a scholarship from the Greek State Foundation. We gratefully acknowledge Dr R. M. Palmer (Division of Nutrition, Pregnancy and Development, RRI, Aberdeen, UK) for useful comments on the manuscript and Dr G. Zuur (BioSS, RRI, Aberdeen, UK) for advice on regression analyses.

\section{References}

Antipatis C, Ashworth CJ \& Grant G (1996) Effects of maternal vitamin A status on prenatal development in rats. Journal of Reproduction and Fertility Abstract Series 18, Abstr. 82.

Biesalski HK, Hemmes C, Hanafy ME, Weiser H, Zschaebitz H \& Stoff E (1996) Long term administration of high dose vitamin A to rats does not cause fetal malformations: macroscopic, skeletal and physicochemical findings. Journal of Nutrition 126, $973-$ 983.

Boren HG, Pauley J, Wright EC, Kaufman DG, Smith JM \& Harris CC (1974) Cell populations in the hamster tracheal epithelium in relation to vitamin A status. International Journal of Vitamin Nutrition and Research, 44, 382-390.

Chytil F (1992) The lungs and vitamin A. American Journal of Physiology 262, L517-L527.

Collins MD, Tzimas G, Hummler H, Bugrin H \& Nau H (1994) Comparative teratology and transplacental pharmacokinetics of all-trans retinoic acid, 13-cis retinoic acid and retinyl palmitate following daily administrations in rats. Toxicology Applied Pharmacology 127, 132-144.

Dann WJ (1932) The transmission of vitamin A from parents to young in mammals. Biochemical Journal 26, 1072-1080.

DeLuca LM (1991) Retinoids and their receptors in differentiation, embryogenesis and neoplasia. FASEB Journal 5, 2924-2933.

Fraslon C \& Bourbon JR (1994) Retinoids control surfactant phospholipid biosynthesis in fetal rat lung. American Journal of Physiology 266, L705-L712.

Gardner EM \& Ross CA (1993) Dietary vitamin A restriction produces marginal vitamin A status in young rats. Journal of Nutrition 123, 1435-1443.

Grant G, Dorward PM \& Pusztai A (1993) Pancreatic enlargement is evident in rats fed diets containing raw soybeans or cowpeas for 800 days but not in those fed diets based on kidney beans or lupinseed. Journal of Nutrition 123, 2207-2215.

Hess D, Keller HE, Oberlin B, Bonfanti R \& Schuep W (1991) Simultaneous determination of retinol, tocopherols, carotenes and lycopene in plasma by means of high performance liquid chromatography on reverse phase. International Journal of Vitamin Nutrition and Research 61, 232-238.

Ismaldi SD \& Olson JA (1981) Dynamics of the fetal distribution and transfer of vitamin A between rat fetuses and their mother. International Journal of Vitamin Nutrition and Research $\mathbf{5 2}$, $11-18$.
Katz J, Khatry SK, West KP, Humphrey JH, Leclerq SC, Pradhan EK, Pohkrel RP \& Sommer A (1995) Night blindness is prevalent during pregnancy and lactation in rural Nepal. Journal of Nutrition 125, 2122-2127.

Lelievre-Pegorier M, Vilar J, Ferrier ML, Moreau E, Freund N, Gilbert T \& Merlet-Benichou C (1998) Mild vitamin A deficiency leads to inborn nephron deficit in the rat. Kidney International 54, 1455-1462.

Lovtrup S \& Ross K (1961) Observation and chemical determinations of deoxyribose nucleic acid in animal tissues. Biochemica et Biophysica Acta 53, 1-10.

Mason KE (1935) Fetal death, prolonged gestation and difficult parturition in the rat because of vitamin A deficiency. American Journal of Anatomy 57, 303-349.

National Research Council (1995) Nutrient Requirements of Laboratory Animals, 4th revised ed. Washington, DC: National Academy Press.

Schacterle GR \& Pollack RL (1973) A simplified method for the quantitative assay of small amounts of protein in biologic material. Analytical Biochemistry 51, 654-655.

Smith SM, Dickman ED, Thompson RP, Sinning AR, Wunsch AM \& Markwald RR (1997) Retinoic acid directs cardiac laterality and the expression of early markers of precardiac asymmetry. Developmental Biology 182, 162-171.

Sneider WC (1967) Determination of nucleic acids in tissues by pentose analyses. Methods of Enzymology 3, 680-684.

Takahashi YI, Smith ES, Winick M \& Goodman DS (1975) Vitamin A deficiency and fetal growth and development in the rat. Journal of Nutrition 105, 1299-1310.

Takahashi YI, Smith JE \& Goodman DS (1977) Vitamin A and retinol binding protein metabolism during fetal development in the rat. American Journal of Physiology 233, E263-E272.

Thompson JN, Howell J McC \& Pitt GAJ (1964) Vitamin A and reproduction in the rat. Proceedings of the Royal Society of London Series B Biological Sciences 159, 510-535.

Underwood BA (1994) Maternal vitamin A status and its importance in infancy and childhood. American Journal of Clinical Nutrition 59, 517S-524S.

Wallingford JC \& Underwood BA (1986) Vitamin A deficiency in pregnancy, lactation and the nursing child. In Vitamin A Deficiency and its Control, pp. 101-151 [CJ Bauernfield, editor]. New York: NY: Academic Press.

Wallingford JC \& Underwood BA (1987) Vitamin A status needed to maintain vitamin A concentrations in nonhepatic tissues of the pregnant rat. Journal of Nutrition 117, 1410-1415.

Wellik DM \& Deluca HF (1995) Retinol in addition to retinoic acid is required for successful gestation of vitamin A deficient rats. Biology of Reproduction 53, 1392-1397.

West KP, Howard GR \& Sommer A (1989) Vitamin A and infection: public health implications. Annual Reviews of Nutrition 9, 63-86.

Wilson JG, Roth CB \& Warkany J (1953) An analysis of the syndrome of malformations induced by maternal vitamin A deficiency. Effects of restoration of vitamin A at various times during gestation. American Journal of Anatomy 92, 189-217. 